\title{
EXPERIMENTAL STUDY ON THE THERMAL PERFORMANCE OF A HEAT SINK WITH PERFORATED WAVY FINS
}

\author{
N. Y. Abdel-Shafi \\ Department of Mechanical Engineering, Faculty of Engineering, \\ Assiut University, Assiut 71516, EGYPT
}

(Received April 28, 2009 Accepted May 23, 2009)

\begin{abstract}
This paper presents experimental results of heat transfer and friction in a horizontal rectangular duct equipped with perforated wavy heat sink. The duct has a cross-sectional area of $0.06 \times 0.36 \mathrm{~m}^{2}$. The heat sink fin has many perforations and is bent to form a wavy shape. The wavy perforated fins are oriented and fixed perpendicular to the heat sink base. Many different heat sinks of the same width and height, with different fins structure have been investigated (fourteen heat sinks). The Reynolds number, Re, is ranged from 16500 to 22000. The dissipated power was 100 $W\left(4630 \mathrm{~W} / \mathrm{m}^{2}\right)$. Experimental work is performed for fins divergence angles, $2 \alpha$, from 15 to 45 degree, the diameter of the fins perforations, $D$, was 2, 3 and $4 \mathrm{~mm}$, and the holes pitch is varied from 5 to $28 \mathrm{~mm}$. The results showed that the average Nusselt number, $\mathrm{Nu}$, increases with Re increasing and that for all the studied configurations, the most effective parameter on the $\mathrm{Nu}$, was found to be fin divergence angle. Correlations are obtained for the average Nusselt number utilizing the present measurements within the investigated range of different parameters.
\end{abstract}

KEYWORDS: Heat sink, perforated fins, wavy fins, cooling of electronics.

\section{INTRODUCTION}

The continuing increase of power densities in electronic devices and the simultaneous drive to reduce the size and weight of electronic products have led to an increased importance of thermal study issues in this industry. More effective cooling techniques are necessary to enhance the rate of power dissipation of these devices, maintaining its operating temperatures at a satisfactory level. It is a well-established fact that high temperature is the leading cause of component failure in power electronics [1]. The task of electronic components cooling has never been simple and has only become more difficult in recent years as the power electronics industry pushes towards devices with higher power densities. Over the years, many methods have been developed to solve the problem of cooling electronics devices [1-2]. The most common method for electronic devices cooling is the use of heat sinks. Such devices include a stereo equipment, computing devices, communications equipment, and new applications in the automotive industry.

There are various types of heat sinks according to the determine applicability as a general cooling product. Various structures and profiles are found for heat sinks. The ones that are commonly used in power electronics are: parallel-plate fins, pin fins, 
and folded fins, which, besides increasing the surface area density of the heat sink, also improves the convection heat transfer coefficients [2-4]. In addition to traditional heat sink fins profile, there is a vast range of microprocessors on the market which each has specific requirements for heat sink design. Therefore, attempts have been made to overcome these adverse effects by development of different designs of the heat sink. Another way of improving the heat transfer characteristics is to employ attachments with perforations [5-6].

Fin optimization is a very important way to enhance heat transfer performance and minimize the pressure drop across heat sinks. There are several studies conducted on fin geometry design and array optimization. By far the most frequently used type of heat sink is the parallel-plate heat sink. Researchers have worked at characterizing their performance and optimizing the design parameters associated with them [7]. Another popular type of heat sink commonly used in power electronic devices is the pin-fin heat sink. The pin-fin heat sink can be a very useful alternative to the parallel plate heat sink. Many researchers have developed optimization techniques for these heat sinks for various applications and cooling environments. Kim and Webb [8] compared the performances of in-line and staggered round pin-fin heat sinks to that of a parallel-plate heat sink and an offset strip-fin heat sink in a cross-flow forced convection arrangement. They found that the parallel-plate and the staggered strip-fin heat sinks provided a significantly lower convective thermal resistance.

In literature, few studies on the performance of heat sinks with wavy profiles fins are reported [9-10]. Abdel-Shafi [10] performed experimental study to compare the thermal performance of heat sinks with different fin designs including wavy fins and folded fins. The thermal performance is evaluated by comparing the thermal resistance of the heat sinks at equal average velocity and equal dissipated power. However, the study of wavy fin heat sink is limited.

Another way of improving the heat transfer characteristics is to employ attachment with perforations. In this case, the improvement in the flow (thus the enhancement in the heat transfer) is brought about by the multiple jets like flows through the perforations. Shaeri and Yaghoubi [11-12] studied three dimensional laminar fluid flow and heat transfer of a heated array of rectangular perforated and solid fins attached on a flat surface numerically. They reported that, the values of perforated fin effectiveness are always positive which show an increase in the heat transfer rate due to use of perforated fins.

Wirtz and co-workers [13] were among the first to investigate the heat transfer performance of the heat sink based on screen-fin technology. In this study, the fin structure consists of a screen-fin oriented perpendicular to the heat sink base, and laid out in a serpentine arrangement. A semi-empirical model is developed to predict the pressure drop, thermal performance and to design prototype heat sinks. It is reported that, by screen-fin technology, the best performance of this kind of heat sink with external dimensions: $76.2 \mathrm{~mm}$ width, $63.5 \mathrm{~mm}$ depth and $38.1 \mathrm{~mm}$ height screenlaminate fins is $4.3 \mathrm{Watt} /{ }^{\circ} \mathrm{C}$ at $62.3 \mathrm{~Pa}$ pressure drop of air flow through the heat sink.

The above literature review shows that the previous studies have investigated heat transfer enhancement from a traditional heat sink fins profile and a very few studies have concentrated on the heat transfer from heat sink with wavy and perforated fins. However, a detailed discussion about thermal performance of wavy and perforated heat sink has not yet been completed. The aim of this paper is to address 
some issues not considered in the previous work. As mentioned earlier, perforations on the fins will lead to the formation of the jet like flows through the holes, which cause heat transfer enhancement. For this reason, the paper aim is to determine heat transfer and friction factor characteristics of the wavy perforated fins.

In this study, the author proposes an advanced concept on the enhancement technique in forced convection heat transfer and also on the performance of an advanced fin. The fin has many perforations and was bent to form a wavy shape. The mechanism of the heat transfer enhancement of the advanced heat sink is experimentally studied by changing the heat sink configuration.

\section{EXPERIMENTAL SET-UP}

A schematic diagram of experimental setup is illustrated in Fig. 1. The air is used as a coolant. Experimental setup mainly consists of wind tunnel (duct), test section, blower, and data collection system. Ambient air is drawn into a rectangular wind tunnel containing the removable test section. The following paragraphs give a detailed description about various parts of experimental set-up.

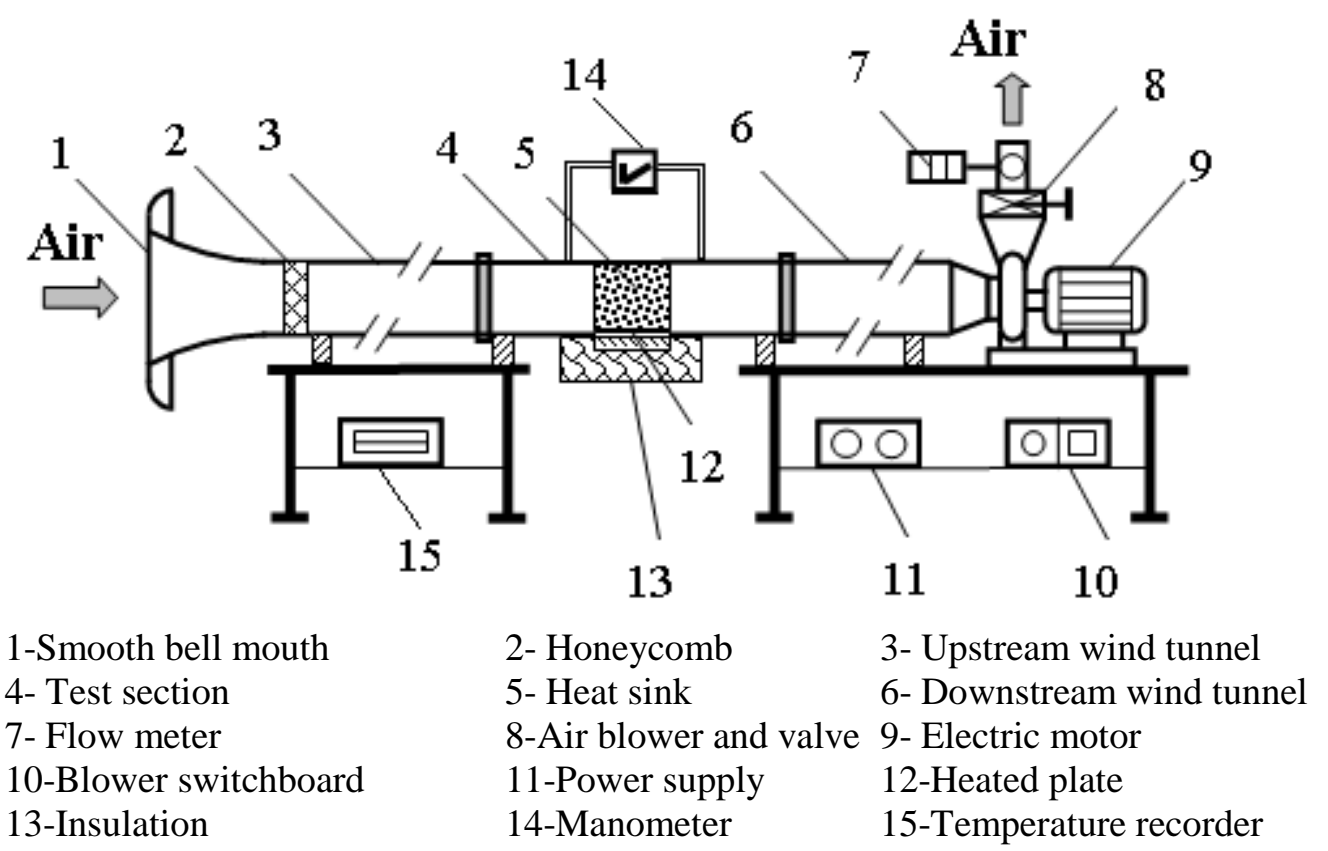

Fig. 1. Schematic diagram of experimental apparatus

\subsection{Wind Tunnel}

The wind tunnel is fabricated completely from wood of $0.02 \mathrm{~m}$ thickness. It has total length of $7.2 \mathrm{~m}$ (including test section length) with internal cross section area of $0.36 \mathrm{~m}$ width and $0.06 \mathrm{~m}$ height. It is operated in suction mode and positioned horizontally. A bell mouth section is fitted at entrance of the wind tunnel. Before reaching to the test section, efforts were made to ensure that the air flow was fully developed. To achieve 
this, the air first flows through a wire-screen layer, a honeycomb layer, another wirescreen layer, and a flow developing tunnel region. The test section is located at $5 \mathrm{~m}$ from the tunnel leading edge (upstream). The tunnel is extended by $1 \mathrm{~m}$ downstream of the test section. Afterwards, air passes through a diverging duct of $0.5 \mathrm{~m}$ length before entering the blower.

\subsection{Test Section}

The shape of the test section with the heat sink installed is shown in Fig. 2. It is made of Plexiglas of $0.01 \mathrm{~m}$ thickness with the same upstream and downstream cross section as the wind tunnel cross-section. The length along flow direction is $0.7 \mathrm{~m}$. The heat sink can be easily mounted in the middle of the test section. The heat sink fits on a seat such that the bottom horizontal wall of the test section is flush with the base of the heat sink, and only the fins protrude.

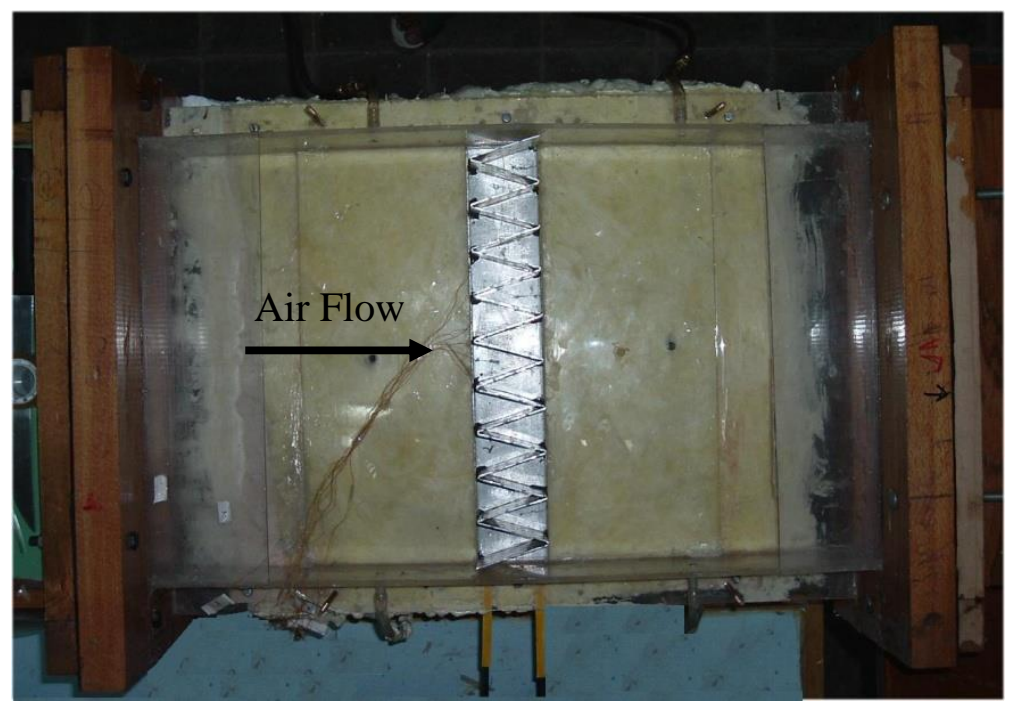

Fig. 2. The shape of the test section with the heat sink installed.

\subsection{Heat Sinks}

Figure 3 shows a view of a perforated wavy heat sink. The heat sink consists of a base plate and a fin structure. All of the heat sinks have base plate dimensions of $0.36 \mathrm{~m}$ length, $0.06 \mathrm{~m}$ width, and $0.006 \mathrm{~m}$ thickness. The fins are made of $0.001 \mathrm{~m}$ thick aluminum sheet as the same base plate material $(\mathrm{k}=151 \mathrm{~W} / \mathrm{m} \mathrm{K})$, and $0.06 \mathrm{~m}$ high. The fins are attached on the upper surface of the base plate as shown in Fig. 3(a). The aluminum sheet is machined by drilling holes with a diameter $\mathrm{D}$. The perforations were in a staggered array. The Aluminum perforated sheet was folded as a serpentine configuration as given in Fig. 3. Wavy slots of $0.001 \mathrm{~m}$ depth and width are cut on the top face of the base plate of the heat sink in order to allow positioning of the wavy fin. A thin layer of thermal glue, with negligible heat resistance is used between the base plate and the wavy fin for better contact. Thus, the structure gives a very big surface area and a reasonable pressure drop by controlling the divergence angle, $2 \alpha$. 
Figure 3 (b) shows the top and side views of a wavy perforated heat sink. The fin structure consists of a wavy perforated fin oriented perpendicular to the heat sink base, and arranged in a serpentine configuration so that the divergence/convergence angle between segments of the fin is $2 \alpha$. As shown in the figure, as the wavy perforated fin is laid out in a serpentine arrangement, the ambient air flows down in a converging section (in-through the perforated fin and out-through a diverging section). Such arrangement provides an increase in the surface area of heat transfer. It also reduces the superficial mass velocity incident on the perforated lamination, and hence effectively controlling the coolant pressure drop. Fourteen different fins of the same width $(h=$ $0.06 \mathrm{~m})$ and thickness $(t=0.001 \mathrm{~m})$, with different divergence/convergence angles and perforations, are used. The perforated fins have a different hole-diameter D and holecenter to hole-center spacing P. Table 1 summarizes the different configuration parameters investigated in this study.

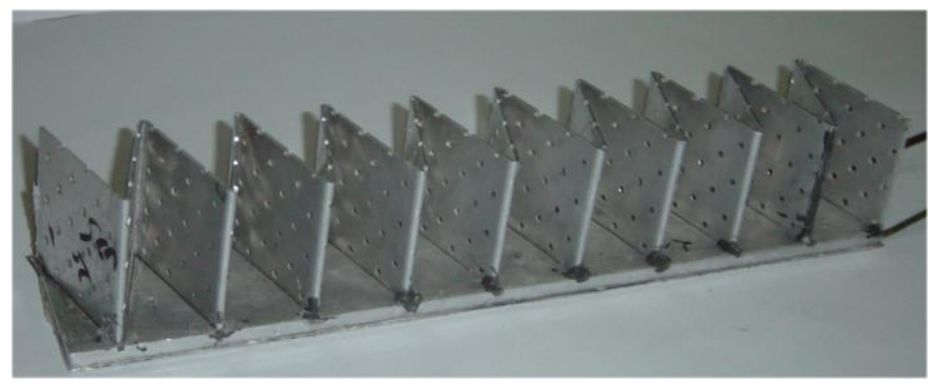

Fig. 3 (a). Shape of the heat sink with perforated wavy fins.

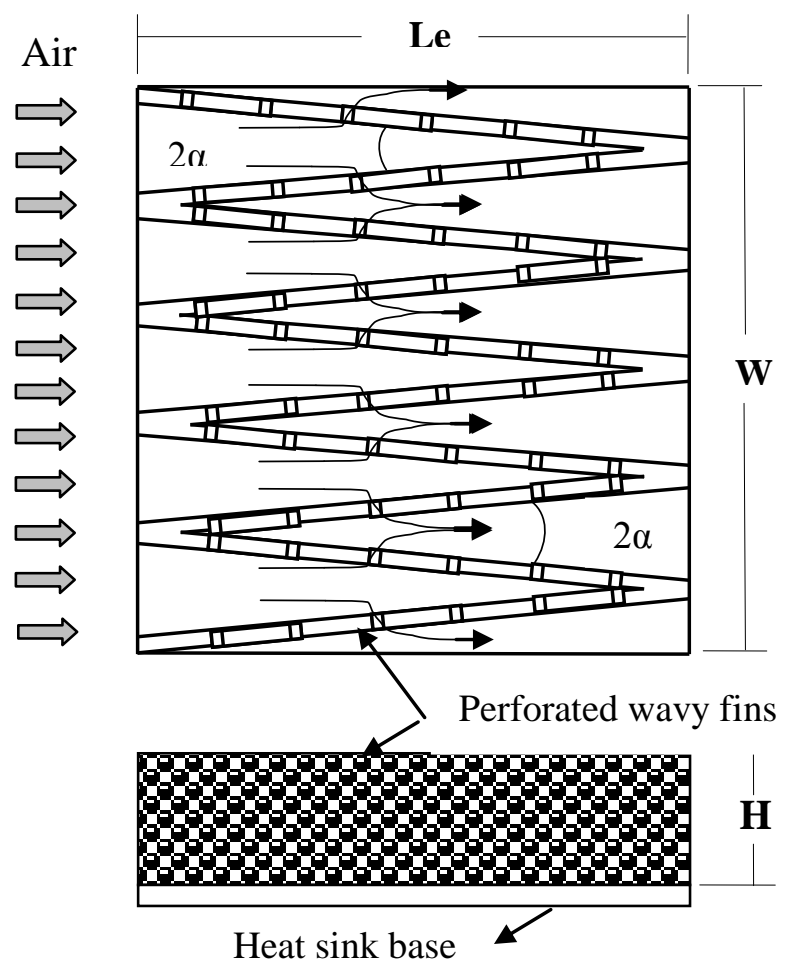

Fig. 3 (b). Schematic of the heat sink with perforated wavy fins. 


\subsection{Heating Unit}

The electric power is dissipated in the base of the heat sink using a very thin thermofoil heater (Nickel / Chromium). The heater was inserted between two sheets of mica, which has the same dimensions as the base plate of the heat sink. The heater and mica sheets are considered as sandwich between the heat sink base and an Aluminum plate with a thickness of $0.006 \mathrm{~m}$. The sandwich is clamped together to provide good thermal contact between the heater and the heat sink base. The total electric resistance of the heater is $4 \Omega$. The power of the heater is supplied by a DC power supply (Model GPC-3030D), whose voltage is stabilized using two stabilizers. The heat flux released from the heating element was adjusted by changing the voltage of the power supply. To minimize the heat loss, all sides of the heater are completely insulated except that towards the heat sink base plate. Tests were run with the amount of dissipated power equals $100 \mathrm{~W}\left(4630 \mathrm{~W} / \mathrm{m}^{2}\right)$.

Table (1) Different perforated wavy fins configuration parameters.

\begin{tabular}{|c|c|c|c|c|c|c|c|c|c|c|c|c|c|c|}
\hline $\mathrm{D}(\mathrm{mm})$ & 2 & 2 & 3 & 3 & 3 & 4 & 4 & 4 & 4 & 4 & 4 & 4 & 4 & 4 \\
\hline $\mathrm{P}(\mathrm{mm})$ & 5 & 5 & 18 & 18 & 18 & 8 & 8 & 8 & 23 & 23 & 23 & 28 & 28 & 28 \\
\hline $\begin{array}{c}2 \alpha \\
\text { (degree })\end{array}$ & 15 & 30 & 15 & 30 & 45 & 15 & 30 & 45 & 15 & 30 & 45 & 15 & 30 & 45 \\
\hline
\end{tabular}

\subsection{Data Collection System}

Type-J thermocouples of $0.1 \mathrm{~mm}$ diameter were employed for temperature measurements. Five thermocouples were pressed in the base of the heat sink through a small hole that drilled into the base. Thermocouples were equally spaced along the base plate among the fins. Three additional thermocouples were positioned along the height of the middle fin. The average temperature reading of the heat sink at steady state is maintained. The inlet and exit bulk air temperatures are monitored by averaging the readings of two thermocouples located at the upstream centerline of the wind tunnel, and another three thermocouples inserted downstream of the test section. The thermocouples were connected to a digital temperature recorder "Digister II" with an accuracy of $0.1 \mathrm{C}$. Nearly one hour is required to reach the steady state condition. All thermocouples were calibrated within $\pm 0.1 \mathrm{C}$ deviation before being used in the experimental work.

The velocity of the air flow over the heat sink has five different values obtained using a variable speed motor to rotate the blower. The blower is of airfoil fantype driven by a three-phase electric motor. The mass flow rate is controlled by a flow regulator valve located at the blower exit.

The pressure drop across the heat sink was determined using two static pressure taps located $100 \mathrm{~mm}$ upstream and downstream of the heat sink and an inclined glass tube water manometer.

\section{EXPERIMENTAL PROCEDURE}

Tests were carried out for 14 test samples at different air mass flow rates. During a typical experimental run, the procedure can be outlined as follows: 
1- The heat input is adjusted to a desired value in the power supply unit.

2- Air mass flow rate is adjusted until the pre-specified value is achieved.

3- The pressure drop, air temperatures and the temperature distributions on the heat sink are recorded after the steady state is reached.

4- After completion of data recording, the procedure is repeated, starting with step 2 again to carry out the experiments with the new air mass flow rate.

5- All experiments were performed twice, to check the repeatability of the data.

\section{DATA REDUCTION}

The air friction and heat transfer rate can be evaluated by the friction factor and Nusselt number. They are plotted as a function of the Reynolds number. The convective heat transfer, $Q_{c o n v}$, from the electrically heated test surface is calculated as:

$$
Q_{\text {conv }}=Q_{\text {elect }}-Q_{\text {loss }}
$$

where $Q$ indicates the heat transfer rate and subscripts conv, elect, and loss denote convection, electrical, and losses, respectively. The electrical heat input is calculated from the electrical potential and current supplied to the surface as:

$$
Q_{\text {elect }}=V I
$$

where $V$ and $I$ are the voltage drop and current applied across the heater, respectively. The total heat losses through the test section can be neglected. The heat transfer from the heat sink by convection can be expressed as:

$$
Q_{\text {conv }}=h_{a v} A_{\text {tot }}\left[T_{S}-\left(\frac{T_{\text {in }}+T_{\text {out }}}{2}\right)\right]
$$

Therefore, the average convective heat transfer coefficient based on the total heat transfer surface area can be given by:

$$
h_{a v}=\frac{Q_{\text {conv }}}{A_{\text {tot }}\left[T_{S}-\frac{T_{\text {in }}+T_{\text {out }}}{2}\right]}
$$

where $T_{s}$, is the average heat sink surface temperature; $T_{\text {out }}$ and $T_{\text {in }}$, the mean temperatures of the air at the outlet and the inlet, respectively; and $A_{\text {tot }}$, is the total surface area. The total area is equal to the sum of the projected area (heat sink base area) and the surface area contribution from the perforated wavy fins. Figure 4 shows the relation between the fins perforated area and the sectional area of a unit element. Therefore, the projected and the total area can be calculated as:

$$
A_{p}=W L_{e}
$$

where, $W$ and $L e$ are the width and the length of the heat sink base plate, respectively. $A_{t o t}=A_{p}+2$ (fins surface area -fins perforated area)

The fins perforated area, $A_{s t}$, can be calculated by:

$$
A_{s t}=n\left(\frac{\pi \cdot D^{2}}{4}\right)
$$

Where, $n$ is the number of holes drilled through a fin, and $D$ is the diameter of a hole. 

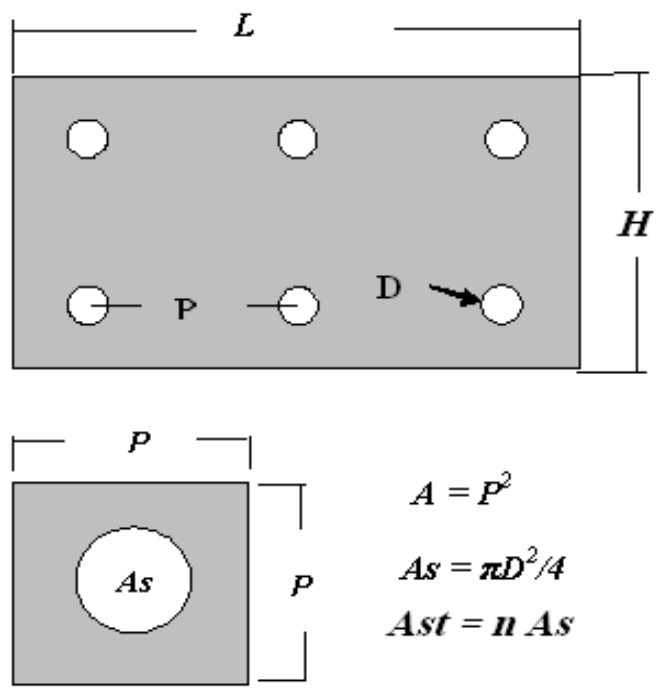

Unit element

Fig. 4. A perforated fin and its corresponding unit element

The number of holes can be given by:

$$
n=\frac{L \cdot H}{p^{2}}=\frac{W \cdot H}{\sin \alpha \cdot p^{2}}
$$

From equations (6) and (7), the fins perforated area can be calculated as:

$$
A_{s t}=\frac{W \cdot H}{\sin \alpha} \frac{\pi}{4}\left(\frac{D}{p}\right)^{2}
$$

where $P, H$, and $\alpha$, are the pitch of the perforated fins, the height of the fins, and the divergence half angle, respectively.

Hence, the total fins surface area can be expressed as:

$$
A_{t o t}=W L_{e}+\frac{2 W \cdot H}{\sin \alpha}\left[1-\frac{\pi}{4}\left(\frac{D}{p}\right)^{2}\right]
$$

The average Nusselt number definitions based on the total surface is given as the following:

$$
N u=\frac{h_{a v} D_{h}}{k}
$$

where $D_{h}$ is the tunnel hydraulic diameter given by:

$$
D_{h}=\frac{4 W H}{2(W+H)}
$$

The Reynolds number is calculated on the basis of tunnel average velocity and tunnel hydraulic diameter defined by: 


$$
\operatorname{Re}=\frac{\rho V_{D} D_{h}}{\mu}
$$

where $\rho$ is the air density, $\mu$ is the air viscosity, and $v_{D}$ is the air average velocity. The friction factor is evaluated from the measured value of pressure drop across the test section using the following equation:

$$
f=\frac{2 \Delta p D_{h}}{L \rho V_{D}^{2}}
$$

where $\Delta p$ is the pressure drop across the heated test section and $L$ is the length of the heat sink.

In all calculations, the values of thermo physical properties of air were obtained at the bulk mean temperature, as:

$$
T_{m}=\frac{T_{\text {in }}+T_{\text {out }}}{2}
$$

\section{RESULTS AND DISCUSSION}

The literature review of the heat sink with perforated wavy fins concluded that a very few work is given for experimental or numerical study. To confirm the proposed experimental system, some experimental work is carried out without any fins attached to the heat sink base (i.e., smooth duct). There are numerous investigations and empirical correlations for smooth plain average Nusselt number and friction factor are given in the literature. In this study, average Nusselt numbers and friction factors are determined at smooth duct for different mass flow rates. Then, the smooth average Nusselt number, $N u_{s}$, and friction factor, $f_{s}$, are compared with the correlation for a smooth rectangular duct given by eqn. (15), Sara et al. [14].

$$
\begin{aligned}
& N u_{s}=0.0919 \operatorname{Re}^{0.706} \operatorname{Pr}^{0.333} \\
& f_{s}=0.316 \operatorname{Re}^{-0.25}
\end{aligned}
$$

$$
6670 \leq \operatorname{Re} \leq 40000
$$

Figures (5) and (6) show a comparison between the experimental study and the predicted values of $N u_{s}$, and $f_{s}$. It can be seen that the deviation between the experimental results and correlations has been found to be under the limits of $\pm 10 \%$. This ensures that the set-up can be used for accurate data collection.

The effect of fins structure on the heat transfer is investigated by examining each design parameter including the ratio between the pitch and the diameter of the perforations, $P / D$, and the divergence angle, $\alpha$. The present study selected the Reynolds numbers, $R e$, with range from 16500 to 21500 . Figure (7) shows the effect of $P / D$ on the average Nusselt number, $N u$, as a function of Reynolds numbers, $R e$, at $P / D=2$, 2.5, 5.75, 6, and 7 (open area ratios 0.196, 0.127, 0.024, 0.0218 and 0.016, respectively). In this figure, the divergence angle, $2 \alpha$, was fixed at value of 30 degree. It is seen from the figure that, for all configurations of fins, $N u$ increases with $R e$ increasing. The $N u$ average value increased as $P / D$ increased from 2 to 5.75 by a percentage of $11.9 \%, P / D$ from 5.75 to 6 by percentage of $1.8 \%$ and $P / D$ from 6 to 7 
by percentage of $2.1 \%$. The $N u$ values decreases with decreasing the amount $P / D$ at the same Reynolds number. This reduction in $N u$ may be due to air velocity reduction through the holes at the same value of $R e$. Also, the fins having larger values of $P / D$ have higher contact area with fluid in comparison with the fins having small values of $P / D$. In addition, the reason for this can be explained by the effect of the temperature difference between the heat sink base and fin that becomes larger at small ratio of $P / D$. Moreover, higher surface area for same $Q_{\text {conv }}$ tends to lower value of $h_{v}$ from definition (eq. 4), but it has been offset by decrease of $\left(T_{s}-\left(T_{i}+T_{o}\right) / 2\right)$.

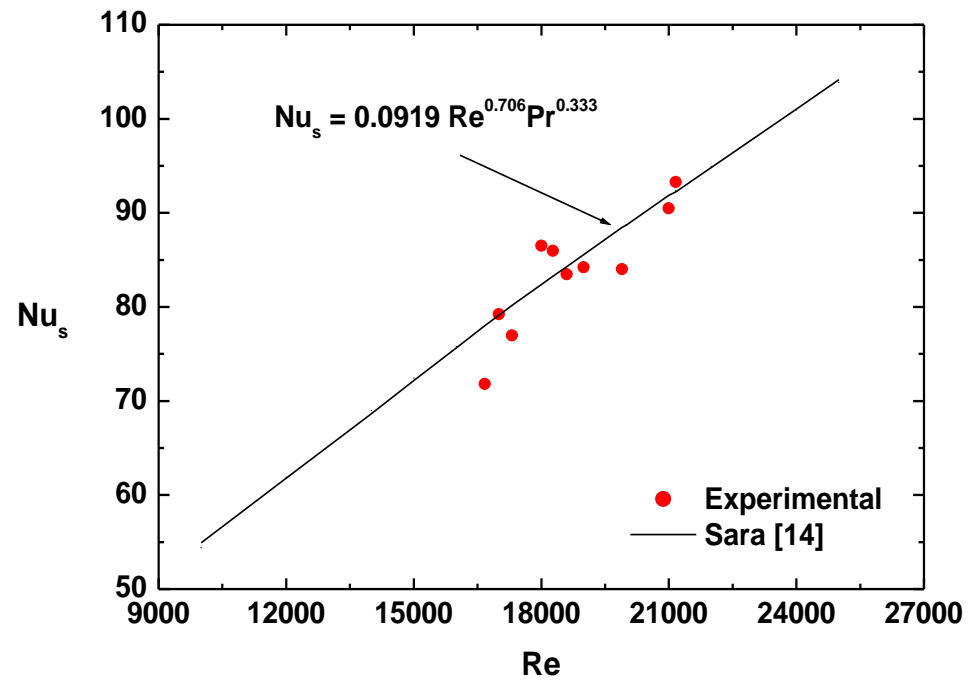

Fig. 5. Comparison of experimental and predicted values of Nusselt number, $N u$, for smooth duct.

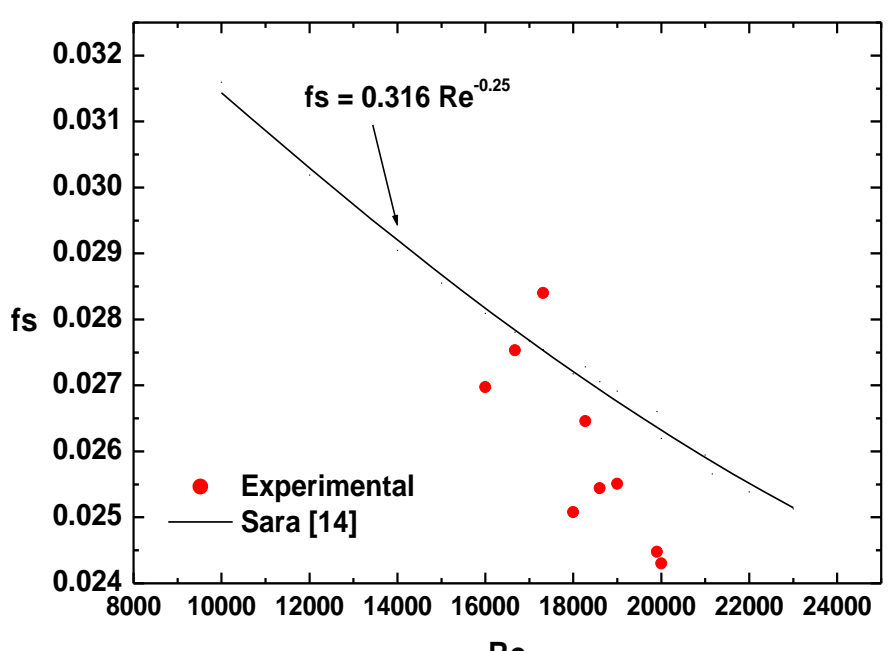

Re

Fig. 6. Comparison of experimental and predicted values of friction factor, $f$, for smooth duct. 


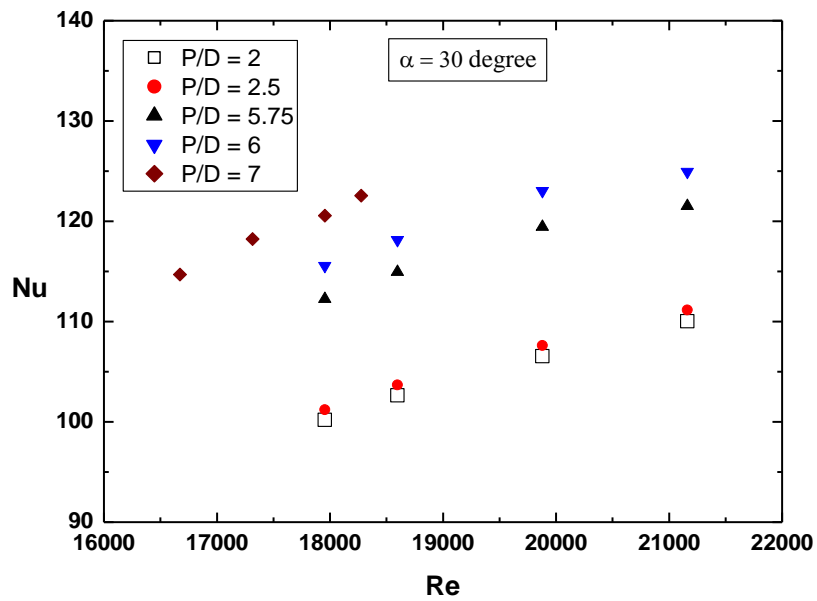

Fig. 7. The variation of average Nusselt number, $N u$, with Reynolds number, $R e$, for different $P / D$ ratios at divergence angle, $2 \alpha=30^{\circ}$.

The divergence angle, $2 \alpha$, is also one of the main factors influencing the performance of the heat sink with perforated wavy fins. Figure $(8, a-b)$ indicates the variation of the $N u$ based on the total surface area with $R e$ for various divergence angle, $(2 \alpha=15,30$ and 45$)$ and the ratio of $P / D$ equals to 2 and 5.75. It is seen from the figure that $N u$ increases with increasing $\alpha$. Also, the average Nusselt number, $N u$, increases compared with $2 \alpha=15$ ( by about $82 \%$ for $2 \alpha=30$, and about $160 \%$ for $2 \alpha=45$ ). It should be noted that, the heat transfer surface area increases with decreasing $\alpha$ since more wavy fin segments can be placed on the heat sink base. However, at fixed flow rate, an increase in surface area will result in a decrease in flow velocity. This situation can be explained as a decrease of the flow mixing among the fins. Thus, when $\alpha$ increases, the effect of mixing of the flow is considering increasing. This tends to increase the $N u$. Note again that as $A_{\text {tot }}$ increases $h_{v}$ tends to decrease, for same $Q_{c o n v}$. This effect might be larger than the effect of changing $\left(T_{s}-\left(T_{i}+T_{o}\right) / 2\right)$.

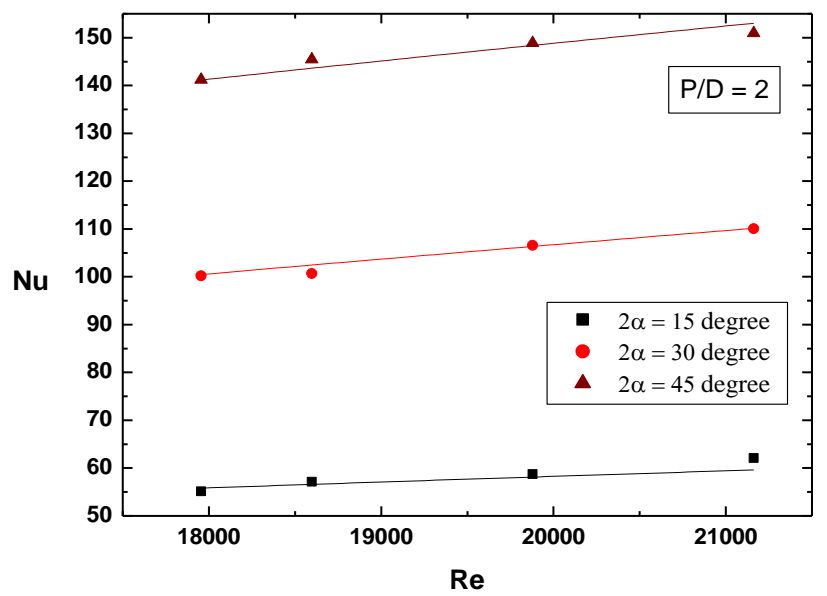

Fig. 8.a. The variation of average Nusselt number, $N u$, with Reynolds number, $R e$, for different divergence angle, $\alpha$, at $P / D$ values of 2 . 


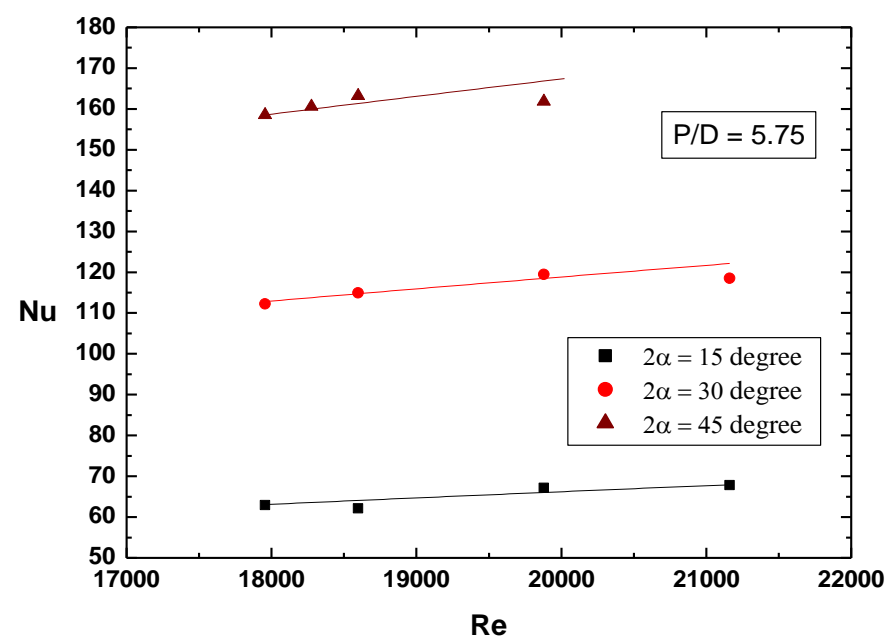

Fig. 8.b. The variation of average Nusselt number, $N u$, with Reynolds number, $R e$, for different divergence angle, $\alpha$, at $P / D$ values of 5.75 .

As mentioned earlier a very few work is published in the area of heat sink with wavy perforated fins and consequently the mechanism of the heat transfer is not fully contributed. In this study, the author attempted to introduce a dimensionless correlation for the $N u$. As concluded from the experimental results, the proposed correlation is fitted to all experimental values to describe $N u$ with respect to $R e, P / D$ and $\alpha$ as follows:

$$
N u=14.923 \operatorname{Re}^{0.3}\left(\frac{p}{D}\right)^{0.12}(\tan \alpha)^{0.844}
$$

This correlation is valid for $\left\{\begin{array}{l}16000 \leq \operatorname{Re} \leq 22000 \\ 15^{\circ} \leq 2 \alpha \leq 45^{\circ} \\ 2 \leq P / D \leq 7\end{array}\right.$

The experimental results are performed with the correlation given in equation (16) with maximum uncertainty value of $\pm 4.5 \%$. Figures (9-a, b and c) show the correlation of $\mathrm{Nu}$, expressed in equation (16), with the experimental results for comparison. As shown from figure, good agreement between the experimental results and this correlation is observed.

Figure (10) shows the variation of friction factor, $f$, with Reynolds number, $R e$. The figure also shows that the friction factor tend to decrease with increase in Re. Also, it is observed that the friction factor decreases with fin configuration having divergence angle, $2 \alpha$, equals to $45^{\circ}$. The values of $f$ is minimum with respected to two the other two fins configuration tested $\left(2 \alpha=15^{\circ}\right.$ and $\left.2 \alpha=30^{\circ}\right)$. The reason of reduction of $f$ can be explained that the surface effect of fin becomes smaller. At the same time, when the ratio $P / D$ increases (small open area ratio), the friction factor increases also. This leads to more resistance to the flow. 


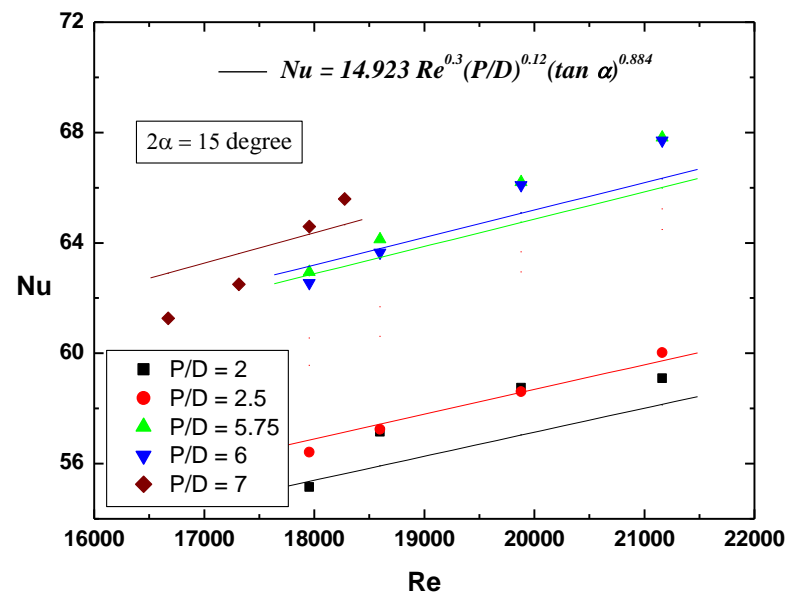

(a) $2 \alpha=15$ degree.

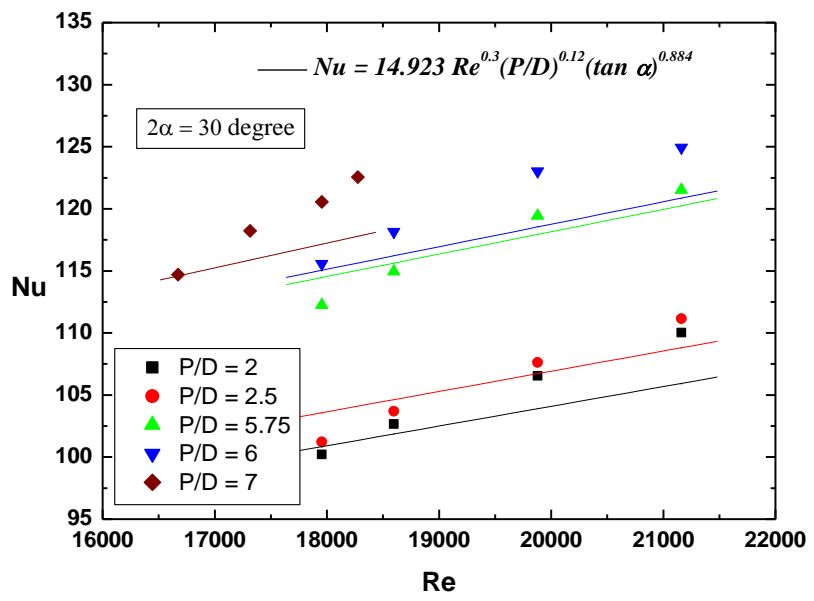

(b) $2 \alpha=30$ degree.

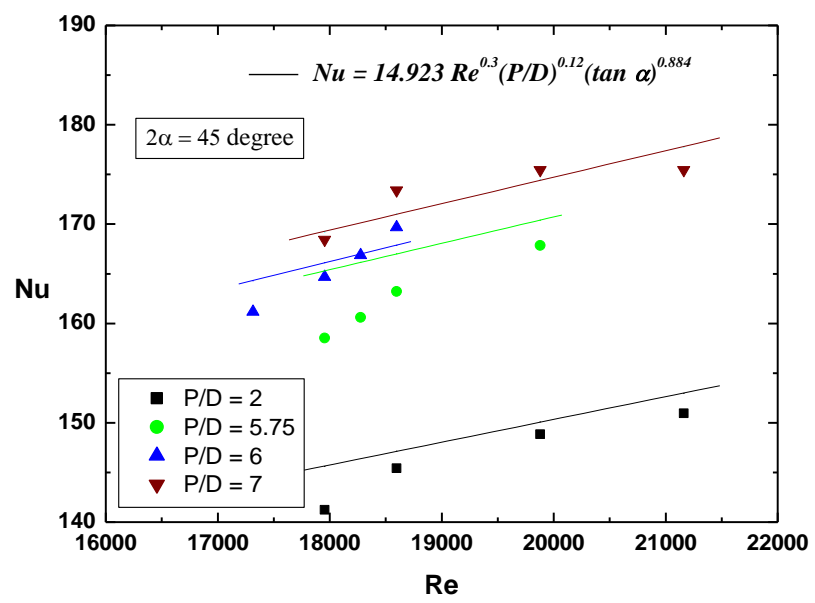

(c) $2 \alpha=45$ degree.

Fig. 9. Comparison of the present experimental data and the correlation of average Nusselt number, $N u$, (Eq. 14) for different values of $P / D$. 


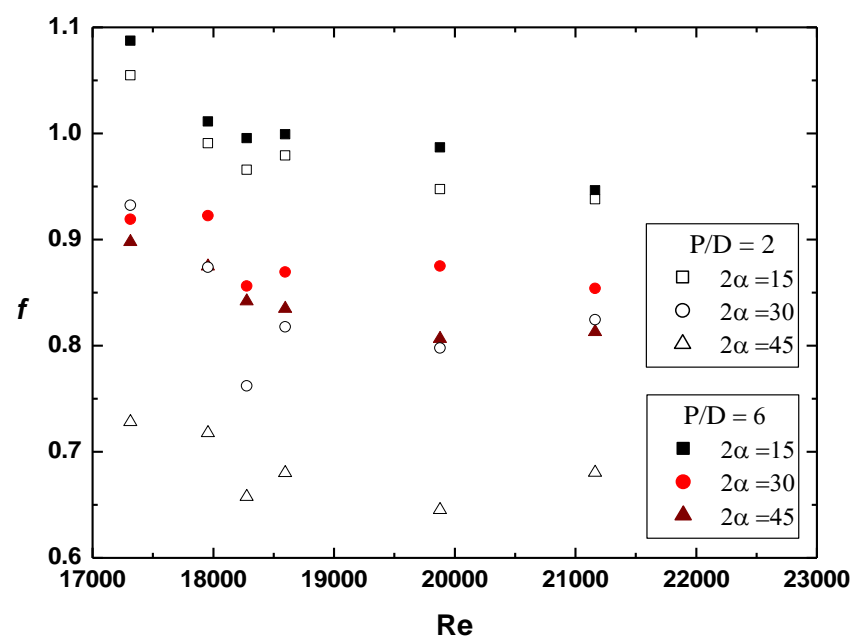

Fig. 10. Variation of friction factor, $f$, with Reynolds number, $R e$, for various fin geometry.

\section{CONCLUSIONS}

The paper introduced an experimental investigation of a designed heat sink with perforated wavy fins attached on a flat surface in a rectangular duct. The performance of the designed heat sink was investigated under forced air convection conditions and Reynolds number in the range from 16500 to 22000 . The effects of the flow and configuration parameters on the heat transfer and friction factor are performed. The experimental study concluded that:

1- The average Nusselt number, $N u$, generally increases with increasing Reynolds number for all different fin configurations.

2- The average Nusselt number increases with the increased the pitch to diameter ratio, $P / D$, for the fin perforation.

3- The fin with largest value of divergence angle $\left(2 \alpha=45^{\circ}\right)$ has best thermal performance.

4- The friction factor decreases with increasing $R e$ for all different designed fin configurations and vice versa it increases with decreasing $\alpha$ and $P / D$ ratio.

5- According to the experimental work, an approximate correlation is provided for the average Nusselt number as a function of fin geometry, and operating parameters. A comparison study between experimental results and the correlation is also given. The maximum deviation of the predicted values of $\mathrm{Nu}$ is within $4.5 \%$.

In the future study, the author is going to introduce more fin configurations with angle limitations.

\section{REFERENCES}

[1] D.S.Steinberg, "Cooling Techniques for Electronic Equipment", 2nd ed. John Wiley \& Sons, New York, 1991. 
[2] A.D.Kraus and A.Bar-Cohen, "Design and Analysis of Heat Sinks", John Wiley \& Sons, New York, 1995.

[3] H.A.Hassan, I.S.Taha, N.Y.Abdel-Shafi and A.Y.Turk " Three Dimensional Transient Cooling of Enclosure Enhanced by Heat Sink, Part II: Parametric Study" , Journal of Engineering Sciences, vol. 32-No.2, Assiut university, April, 2004.

[4] O.N.Sara, "Performance Analysis of Rectangular Ducts with Staggered Square Pin Fins", Energy Conversion and Management, 44, pp. 1787-1803, 2003.

[5] E.Dorignac, J.J.Vullierme, M.Broussely, C.Foulon, and M.Mokkadem, "Experimental Heat Transfer on the Windward Surface of a Perforated Flat Plate", Int., J. of Thermal Sciences, 44, pp. 885-893, 2005.

[6] B. Sahin and A. Demir, "Thermal Performance Analysis and Optimum Design Parameters of Heat Exchanger Having Perforated Pin Fins", Energy Conversion \&Management, 49, pp. 1684-1695, 2008

[7] S.Lee, "Optimum Design and Selection of Heat Sinks", IEEE Trans., CPMTA, Vol. 18, No. 4, pp. 812-817, 1995.

[8] S. J. Kim, D.-K. Kim, and H. H. Oh, "Comparison of Fluid Flow and Thermal Characteristics of Plate-Fin and Pin-Fin Heat Sinks Subject to a Parallel Flow", Heat Transfer Engineering, 29(2):169-177, 2008.

[9] M. Lorenzini, G. Fabbri and S. Salvigni, "Performance Evaluation of a WavyFin heat Sink for Power Electronics", Applied Thermal Eng., 2006

[10] N. Y. Abdel-Shafi, "Experimental Study of Thermal Performance of Heat Sinks with Folded and Wavy Fins", Proceedings of IMEC2004 International Mechanical Engineering Conference, December 5-8, 2004, Kuwait.

[11] M.R.Shaeri, and M.Yaghoubi, "Thermal Enhancement from Heat Sinks by Using Perforated Fins", Energy Conversion and Management, Vol. 50, pp. 1264-1270, 2009.

[12] M.R.Shaeri, and M.Yaghoubi, "Numerical Analysis of Turbulent Convection Heat Trancfer from an Array of Perforated Fins", Int. J. of heat and fluid flow, Vol. 30, pp. 218-228, 2009.

[13] Chen Li and R.A.Wirtz, "Development of a High Performance Heat Sink Based on Screen Fin Technology", IEEE Trans. CAPT, Vol. 28. No. 1, 2005.

[14] O.N.Sara, T.Pekdemir, S.Yapici, and H.Ersahan, "Thermal Performance Analysis for Solid and Perforated Blocks Attached on a Flat Surface in Duct Flow", Energy Conversion and Management, Vol. 41, pp. 1019-1028, 2000. 


\section{دراسة معملية للأداء الحرارى للبالوعة الحرارية ذات زعانف مثقبة وعلى شكل موجات}

$$
\text { نبيل يس عبد الثافي }
$$

ملخص في هذا البحث يتم عرض نتائج الدراسـات المعطيـة لانتقال الحرارة والاحتكالك للبالوعـة الحراريـة ذات زعانف مثقبة وعلى شكل موجات والمثبتة داخل نفق مستطيل الثكل, مساحة مقطعه 0,36 في عرص 0,06

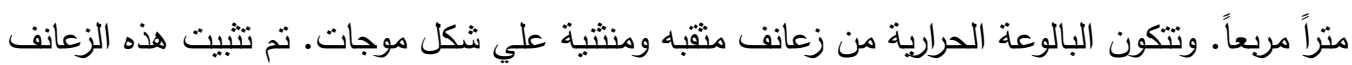

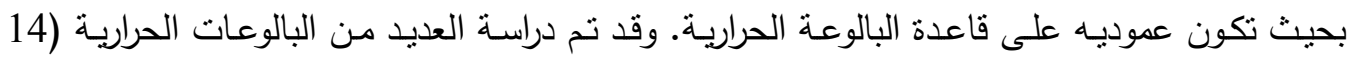
بالوعة) مختلفة الأشكال مـع تثتيت عرض واريه وارتفاع البالوعة فى جميع الحالات (أبعاد البالوعة الحرارية

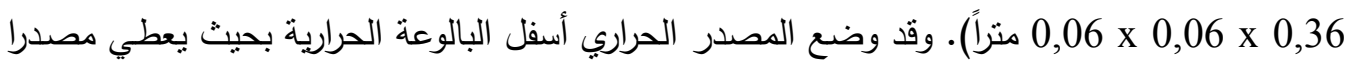

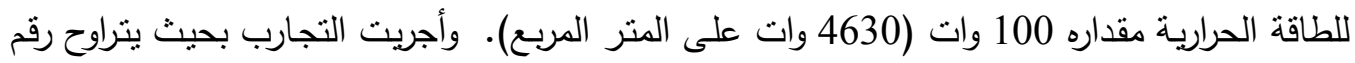
رونولا من 16500 الى 22000, وكذللك زاوية التموج بين الزعانف تتراوح من 15 درجة الى 45 دأل 450 درجة.

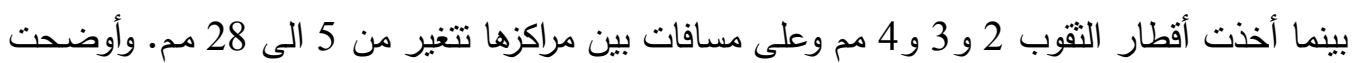

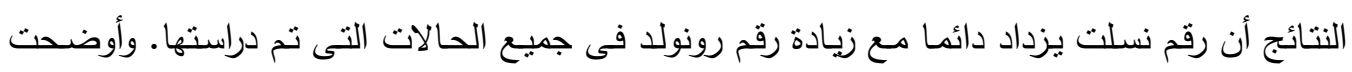
كذلك أن التأثير الأكبر فى رقم نسلت يظهر مع تغير زاوية التموج بين الزعانف. وقد تم استنتاج معادلة

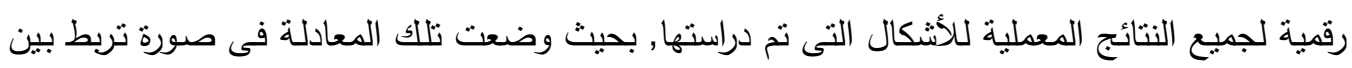
رقم نسلت المتوسط وباقى العوامل التى أخذتها هذه الدراسة فى الاعتبار . 